\title{
BMJ Open Minimum income for healthy living and frailty in adults over 65 years old in the English Longitudinal Study of Ageing: a population-based cohort study
}

\author{
Paul Nicholas Watts, ${ }^{\oplus 1}$ David Blane, ${ }^{2,3}$ Gopalakrishnan Netuveli $i^{3,4}$
}

To cite: Watts PN, Blane D, Netuveli G. Minimum income for healthy living and frailty in adults over 65 years old in the English Longitudinal Study of Ageing: a populationbased cohort study. BMJ Open 2019;9:e025334. doi:10.1136/ bmjopen-2018-025334

- Prepublication history and additional material for this paper are available online. To view these files, please visit the journal online (http://dx.doi org/10.1136/bmjopen-2018025334).

Received 11 July 2018 Revised 7 December 2018 Accepted 15 January 2019

Check for updates

(C) Author(s) (or their employer(s)) 2019. Re-use permitted under CC BY-NC. No commercial re-use. See rights and permissions. Published by BMJ.

${ }^{1}$ School of Health, Sports and Bioscience, University of East London, London, UK

${ }^{2}$ Department of Primary Care and Public Health, Imperial College London, London, UK ${ }^{3}$ International Centre for

Lifecourse Studies in Society and Health (ICLS), Department of Epidemiology and Public Health., University College London,

London, UK

${ }^{4}$ Institute for Health and Human Development, University of East London, London, UK

Correspondence to

David Blane;

d.blane@imperial.ac.uk

\section{ABSTRACT}

Objective To test whether minimum income for healthy living of a person aged 65 years or older $\left(\mathrm{MIHL}_{65}\right)$ is associated with frailty in older adults.

Design and setting Secondary analysis of the English Longitudinal Study of Ageing, a multiwave prospective cohort study in England, UK.

Participants A subset $(n=1342)$ of English Longitudinal Study of Ageing participants, who at wave 1 in 2002 were aged 65 years or older, without any limiting longstanding illnesses, and who had the information required to calculate $\mathrm{MIHL}_{65}$ in 2002, 2004 and 2006 and two measures of frailty in 2008.

Main outcome measures Frailty defined using Fried's phenotype criteria and Rockwood's Index of deficits. Results The odds of frailty in 2008 were significantly higher for participants living below $\mathrm{MIHL}_{65}$ in 2002, both on Fried's phenotype criteria (OR 2.56, 95\% Cl 1.57 to 4.19 ) and Rockwood's Index (OR 2.83, 95\% $\mathrm{Cl} 1.74$ to 4.60 ). These associations remained after adjustment for age and gender for both Fried's phenotype (OR 1.85, 95\% Cl 1.18 to 2.90 ) and Rockwood's Index (OR $2.15,95 \% \mathrm{Cl}$ 1.38 to 3.35$)$. Compared with those whose income during 2002-2006 was always above $\mathrm{MIHL}_{65}$, the odds of frailty in 2008 for those below $\mathrm{MIHL}_{65}$ were two-to-three times higher, with a tendency for the ORs to increase in line with the length of time spent below $\mathrm{MIHL}_{65}$ (ORs (95\% Cls) were: Fried's phenotype, below $\mathrm{MIHL}_{65}$ once: 2.02 (1.23 to 3.34); twice: 2.52 (1.37 to 4.62); thrice: 3.53 (1.65 to 7.55). Rockwood's Index: once: 2.34 (1.41 to 3.86); twice: 3.06 (1.64 to 5.71); thrice: 2.56 (1.22 to 5.34)). These associations remained after adjustment for age and gender on Rockwood's Index, but not Fried's phenotype.

Conclusions These results provide some support for the idea that frailty at older ages is associated with not having sufficient income to lead a healthy life.

\section{INTRODUCTION}

Frailty is a clinical syndrome predominantly of older ages when comorbidities and multimorbidity become more prevalent and require significant informal and formal care. It is a common condition characterised by a decline in function across physical and cognitive systems and a reduced ability to cope with
Strengths and limitations of this study

- Previous studies have not used measures of income with a biologically plausible link to frailty: minimum income for healthy living is a measure with built-in biological plausibility.

- The English Longitudinal Study of Ageing provides a unique opportunity to test the longitudinal relationship between minimum income for healthy living and two measures of frailty.

- The study's strength in economic measures has allowed minimum income for healthy living to be operationalised at multiple survey waves.

- The levels of attrition in the English Longitudinal Study of Ageing is a limitation common in longitudinal studies of older adults.

- The comparatively small size of the subset of participants appropriate to the research questions is a further limitation.

stressors. ${ }^{1}$ Older adults who become frail are at greater risk of death, hospitalisation and being placed in full-time residential care. ${ }^{23}$ In the context of ageing populations, frailty can therefore have consequences for quality of life and health, care and welfare systems. ${ }^{45}$

In the last 10 years, studies have shown that components of adult socioeconomic status, including education ${ }^{6-9}$ and occupation ${ }^{810}$ are associated with frailty in older adults. Furthermore, recent studies have identified a relationship between income and the onset of frailty. ${ }^{6-10}$ Gardiner and colleagues, ${ }^{8}$ found in a 2016 study that participants' ability to manage on income during later life is more strongly associated with frailty trajectories than levels of education in early adulthood or occupational status in midlife. These findings suggest that as adults reach later life and are at greater risk of frailty, income may be the most important component of socioeconomic status. Furthermore, there is greater potential for feasible policy interventions to prevent frailty through changes to income 
levels in later life than there is to change early-adulthood education or midlife occupational status.

A limitation of some previous studies on the relationship between income and frailty is that they have not used detailed economic measures or have relied on participants' perceptions of how easily they manage on their income levels. ${ }^{8}$ Other studies have used income groups that are arbitrary or based on an individual's relative position within the population distribution. ${ }^{6911}$ To our knowledge, there are no previous studies on income and frailty that have used measures of income that are empirically or theoretically related to older adults' ability to lead a healthy life.

Jerry Morris gave to us the concept of a minimum income for healthy living, which the present paper uses to investigate frailty. Morris' thinking was straightforward: a half-century of medical research had established with some certainty the necessities for a healthy life. And, there was little point in lecturing people about healthy living if they lacked the financial means of achieving it. ${ }^{12}$ Morris and colleagues ${ }^{13}$ identified and costed nine minimum requirements for healthy living: diet/nutrition, physical activity, housing, healthcare, psychosocial relations, hygiene, getting about, other costs of social living (eg, clothing) and contingencies/inefficiencies. This idea was first applied to single young adult males ${ }^{14}$ then to people aged 65 years and older. ${ }^{13}$ It is the latter work which is relevant to the present paper. A number of things are particularly noteworthy. First, Morris' estimate of the minimum income for healthy living of people aged 65 years and older $\left(\mathrm{MIHL}_{65}\right)$ excluded the costs of having a chronic illness. This was because these costs varied greatly from one disease to another, thereby underestimating the true $\mathrm{MIHL}_{65}$ of the approximately $40 \%$ of over-65s who have a chronic disease. Second, the State means-tested supplement to its Old Age Pension (Pension Credit Guarantee), designed for those without an occupational or other type of second pension, was several pounds per week below this conservative estimate of the minimum income for healthy living. And finally, this $\mathrm{MIHL}_{65}$ was considerably higher than the level of the State Old Age Pension, meaning that relying solely on the State Old Age Pension for retirement income would potentially damage health. The present paper tests this final point in relation to frailty.

Among its most widely used measures are Fried's Frailty Phenotype ${ }^{2}$ and Rockwood's Frailty Index. ${ }^{15}$ The former of these measures defines frailty as the combination of three or more of: unintentional weight loss, weakness, exhaustion, slow walking speed and low physical activity. The latter measure includes a minimum of 30 items representing accumulated deficits in tests of cognition together with self-reports of difficulty with daily activities, mental and physical health and the presence or not of specific diseases. Frailty is known to vary with a range of demographic factors, to which the present paper adds a social measure with built-in biological and clinical plausibility. Its main research questions are as follows: Does living below $\mathrm{MIHL}_{65}$ predict the risk of becoming frail?; and, if so, are they associated in an accumulative fashion, such that the probability of becoming frail increases with the length of time spent sub-MIHL ${ }_{65}$ ? Subsidiary research questions are the following: (a) Do the two measures of frailty relate differently to $\mathrm{MIHL}_{65}$ ?; (b) Does $\mathrm{MIHL}_{65}$ add anything to conventional economic measures of income at older ages? and (c) Does MIHL $_{65}$ add anything to the age and gender relationships to frailty?

\section{METHODS \\ Data}

The present study's data come from the English Longitudinal Study of Ageing (ELSA) which are available on open academic access. ELSA is a large, nationally representative sample of community-dwelling individuals aged over 50 years and resident in England, originally recruited from previous Health Survey for England participants. It is interdisciplinary by intention, with strengths in economics and biology. The first wave of data collection was in 2002 and repeated measurements on participants have been taken by household survey every 2 years, and by nurse visits for a subset of participants every 4 years, beginning at wave 2 in 2004. ELSA participants self-complete surveys with the support of trained interviewers and complete face-to-face surveys using computer-assisted interviewing. At nurse visits, measures of physical and cognitive functions are taken by trained nurses. Further details on the methods used to collect ELSA data have been published previously. ${ }^{16}$

The core ELSA sample at wave 1 includes 12099 respondents aged 50 and above. A subset of ELSA participants was created who at wave 1 in 2002 were aged 65 years or older, to be relevant to Morris' MIHL $_{65}$ estimate $(n=5541)$. To avoid a potential and plausible link between both income and frailty, we then excluded 2296 participants who had reported and a limiting long-standing illness at wave 1. Limiting long-standing illness was assessed using two questions: (1) 'Do you have any longstanding illness, disability or infirmity? By long-standing I mean anything that has troubled you over a period of time or that is likely to affect you over a period of time' and (2) For respondents who answered 'yes': 'Does this illness or disability limit your activities in any way?' Participants who responded affirmatively to both questions were classified as having a limiting long-standing Illness. Of the remaining initial sample of 3245 at wave 1 , a total of 1648 were in the subset of participants who participated in nurse visits (and therefore provided the data on physical function required to measure frailty). A complete case analysis was conducted after excluding participants with missing data on income at waves 1,2 or $3(n=105)$ and insufficient data to measure frailty at wave $4(n=201)$. This gave a final sample size of 1342 respondents. 


\section{Measures}

Minimum income for healthy living

Morris' estimates of $\mathrm{MIHL}_{65}$, which he calculated for 2005, were recalculated to match the years of ELSA waves 1, 2 and 3. The MIHL was disaggregated into its component parts (diet/nutrition, physical activity, housing, healthcare, psychosocial relations, hygiene, getting about, other costs of social living (eg, clothing) and contingencies/ inefficiencies), expenditure on each component adjusted to the Consumer Price Index in April 2002, 2004 and 2006 and summed to produce a value of $\mathrm{MIHL}_{65}$ in each of these years (see online supplementary file 1 for further details). A binary variable was created to indicate if each ELSA participant met the relevant MIHL $_{65}$ threshold at each of waves 1-3; as well as an ordinal variable (Accumulated $\mathrm{MIHL}_{65}$ ) to indicate the number of waves (between wave 1 and wave 3 ) in which the participant's income was less than the relevant MIHL $_{65}$ threshold.

\section{Frailty}

Fried's Frailty Phenotype was measured using information collected at the ELSA 2008 Nurse Visit and Survey, using definitions adapted from previous studies on frailty using ELSA data. ${ }^{17-19}$ Unintended weight loss was defined as loss of $10 \%$ or more of body weight since ELSA wave 2 or a current Body Mass Index of less than $18.5 \mathrm{~kg} / \mathrm{m}^{2}$, with height measured by portable stadiometer and weight by electronic scales. Weakness was defined as a maximum grip strength in the lowest $20 \%$ of the distribution, after adjusting for gender and Body Mass Index, with grip strength measured as the best of three measurements taken using a dynamometer. Exhaustion was defined as self-perceived, measured as a positive response to either of the Center for Epidemiologic Studies Depression Scale items Felt that everything I did was an effort in the last week or Could not get going in the last week. Slow walking speed was defined as a walking speed in the lowest $20 \%$ of the distribution, after adjusting for gender and height, measured as the mean of the two times taken to walk a distance of eight feet at usual pace. Low physical activity was defined as physical activity in the lowest $20 \%$ of the distribution, measured by survey questions on the frequency and intensity of exercise. Study participants with three or more of these criteria were defined as frail.

The Rockwood Frailty Index was adapted from Marshall and colleagues ${ }^{20}$ and calculated from participant responses to up to 60 survey items (minimum 30), each scaled to a value between 0 and 1 . For binary items like difficulty walking 100 yards, a deficit was scored 1 and no deficit 0 . For Likert scale items like self-reported eyesight, Poor $=1$, Fair $=0.75$, Good=0.5, Very good=0.25, Excellent $=0$. For continuous variables like score on the word recall test, 5th Quintile $=1$, 4th Quintile $=0.75$, 3rd Quintile $=0.5$, 2nd Quintile $=0.25$ and 1st Quintile $=0$. Frailty scores ranging between 0 and 1 were calculated for each participant who had answered at least 30 out of the 60 items by summing the completed item scores then dividing the sum by the number of answered items, ${ }^{21}$ with those having a score of 0.2 or above defined as frail. This cut point of 0.2 has been shown by multiple methods to represent approaching a frail state and is the conventional cut point for the Rockwood Index in previous studies. ${ }^{21}$ Full details of the items used in the Rockwood Index are available in online supplementary file 2 .

\section{Statistical analysis}

Analysis (1): description of the prevalence of living sub-MIHL 65 in 2002, 2004 and 2006 and the prevalence of frailty in 2008, using both the Fried and Rockwood methods. Analysis (2): the relationship between living sub-MIHL $_{65}$ in 2002 and being frail in 2008, by both measures, was estimated using logistic regression, with living above MIHL $_{65}$ in 2002 as the reference category, both before and after adjusting for gender and age (65-74 vs $75+$ ). Analysis (3): the previous analyses were repeated using Accumulated $M I H L_{65}$ during 2002-2006 instead of living sub-MIHL ${ }_{65}$ in 2002, including a test for linear trend. Analysis (4): sample size was expanded from 1342 to 1925 by including those with a limiting long-standing illness in 2002, thereby increasing statistical power at the cost of weakening protection against confounding; analyses 2 and 3 were rerun on this larger sample. Analysis (5): analyses 2, 3 and 4 were rerun using an economic distributional measure of poverty-living below $60 \%$ of the median income-instead of $\mathrm{MIHL}_{65}$, a public health measure. All statistical analyses were conducted with Stata V.14.

\section{Patient and public involvement}

No patients/public were involved in setting the research question or the outcome measures, nor were they involved in developing plans for recruitment, design or implementation of the study. No patients/public were asked to advise on interpretation or writing up of results. There are no plans to disseminate the results of the research to study participants or the relevant patient community.

\section{RESULTS}

Of the sample, $53 \%$ were female and $26 \%$ aged 75 years or older. Nearly $20 \%$ (19.75\%) of the sample were living below $\mathrm{MIHL}_{65}$ in 2002, a value which fell subsequently to $14.4 \%$ in 2004 and $15.5 \%$ in 2006 . In 2008 , nearly $17 \%$ (16.7\%) of the sample were frail on Fried's phenotype criteria; and $18.9 \%$ according to Rockwood's score. There was moderate agreement $(82.9 \%)$ between the two measures of frailty (Cohen's к: 0.41). Descriptive data on participant characteristics, levels of MIHL and frailty are shown in table 1.

Using as the reference category, those sample participants who were not living below MIHL65 in 2002, the OR of being frail in 2008 for those who were living below MIHL65 were 2.56 (95\% CI 1.57 to 4.91 ) on Fried's phenotype criteria and 2.83 (95\% CI 1.74 to 4.60 ) on Rockwood's score- see table 2. After adjustment for age 
Table 1 Descriptive data on sociodemographic characteristics, MIHL, poverty and frailty

\begin{tabular}{|c|c|c|c|c|c|c|c|c|}
\hline & \multicolumn{2}{|c|}{$\begin{array}{l}\text { Wave } 1 \\
2002\end{array}$} & \multicolumn{2}{|c|}{$\begin{array}{l}\text { Wave } 2 \\
2004\end{array}$} & \multicolumn{2}{|c|}{$\begin{array}{l}\text { Wave } 3 \\
2006\end{array}$} & \multicolumn{2}{|c|}{$\begin{array}{l}\text { Wave } 4 \\
2008\end{array}$} \\
\hline & $\mathbf{N}$ & $\%$ & $\mathbf{N}$ & $\%$ & $\mathbf{N}$ & $\%$ & $\mathbf{N}$ & $\%$ \\
\hline Male & 629 & 46.9 & & & & & & \\
\hline $65-74$ years & 995 & 74.1 & & & & & & \\
\hline $75+$ years & 347 & 25.9 & & & & & & \\
\hline $\begin{array}{l}\text { MIHL Poor } \\
\text { (yes) }\end{array}$ & 265 & 19.8 & 193 & 14.4 & 208 & 15.5 & & \\
\hline $\begin{array}{l}\text { Frail } \\
\text { (Rockwood } \\
\text { Index } 0.2 \text { or } \\
\text { above) }\end{array}$ & & & & & & & 248 & 18.9 \\
\hline $\begin{array}{l}\text { Frail (3 } \\
\text { or more } \\
\text { phenotype } \\
\text { criteria) }\end{array}$ & & & & & & & 224 & 16.7 \\
\hline
\end{tabular}

MIHL, minimum income for healthy living.

and gender, these OR values reduced to, respectively, 1.85 (95\% CI 1.18 to 2.90 ) and 2.15 (95\% CI 1.38 to 3.35 ).

Using as the reference category those sample participants who during 2002-2006 had never lived below MIHL $_{65}$, the ORs of being frail on Fried's phenotype criteria in 2008 for those who had lived below MIHL $_{65}$ on one occasion during 2002-2006 were 2.02 (95\% CI 1.23 to 3.34 ), while the equivalent ORs for those who had lived below MIHL $_{65}$ on two or three occasions during 2002-2006 were, respectively 2.52 (95\% CI 1.37 to 4.62 ) and 3.53 (95\% CI 1.65 to 7.55 ) - see table 3 . The equivalent figures on Rockwood's score were 2.34 (95\% CI 1.41 to 3.86 ), 3.06 (95\% CI 1.64 to 5.71 ) and 2.56 (95\% CI 1.22 to 5.34). After adjustment for age and gender, only the associations between Rockwood's measure of frailty in 2008 and having lived below MIHL $_{65}$ on one or two occasions during 2002-2006 remained significant. The test for trend in the adjusted accumulation models was significant for Rockwood's Index, but not Fried's phenotype.

\section{Sensitivity analyses}

To investigate whether some of table 3's adjusted results were influenced by statistical power, the analyses were repeated after removing having a limiting long-standing illness in 2002 from the sample exclusion criteria. Doing so increased the sample size from 1342 to 1925-although at the cost of weakening protection against confounding. Only two results changed, both of which involved Fried's phenotype of frailty, where the increased odds of frailty for those living below $\mathrm{MIHL}_{65}$ once or twice during 20022006 became statistically significant: OR for one occasion 1.54 (95\% CI 1.04 to 2.29$)$; for two occasions 1.61 (95\% CI 1.00 to 2.58 ).

Second, to compare the biological approach of MIHL $_{65}$ with the standard distributional approach of economics, the analyses whose results are presented in table 2 and 3 were rerun using living with an income below $60 \%$ of the median income (in poverty), instead of MIHL ${ }_{-6.5}$. The two approaches produced estimates of similar magnitude, but model fit and strength of association suggested that the biological $\left(\mathrm{MIHL}_{65}\right)$ approach was the better predictor of frailty (see online supplementary file 3).

On an advice from a reviewer, we reran the models using age as a continuous variable with an added quadratic term to investigate non-linear associations. The ORs were slightly attenuated in models adjusted for non-linear age associations (see online supplementary file 4), but there were no substantial changes to the interpretation of the results.

\begin{tabular}{|c|c|c|c|c|c|c|}
\hline \multirow{2}{*}{$\begin{array}{l}\text { MIHL Poor in } \\
2002\end{array}$} & \multirow[b]{2}{*}{$\mathbf{N}$} & \multicolumn{5}{|c|}{ Frail in 2008} \\
\hline & & OR & LCI & UCI & $P$ value & AIC \\
\hline No & 1077 & Ref & & & & 1193.6 \\
\hline Yes & 265 & 2.56 & 1.57 & 4.19 & $<0.001$ & \\
\hline Yes & 265 & 1.85 & 1.18 & 2.90 & 0.007 & \\
\hline \multicolumn{7}{|c|}{ Frailty definition: Rockwood's Index } \\
\hline No & 1077 & Ref & & & & 1260.6 \\
\hline Yes & 265 & 2.83 & 1.74 & 4.60 & $<0.001$ & \\
\hline
\end{tabular}

*Adjusted for age and gender. Significant values $(p<0.05)$ shown in bold.

$\mathrm{AIC}$, Akaike information criterion; LCl, lower confidence interval; MIHL, minimum income for healthy living; UCl, upper confidence interval. 
Table 3 Association between the duration of living below the minimum income for healthy living during 2002-2006 and being frail in 2008, England

\begin{tabular}{|c|c|c|c|c|c|c|c|c|}
\hline \multirow[b]{2}{*}{ Models } & \multirow{2}{*}{$\begin{array}{l}\text { Number of } \\
\text { periods MIHL } \\
\text { poor }\end{array}$} & \multirow[b]{2}{*}{$\mathbf{N}$} & \multicolumn{6}{|c|}{ Frail in 2008} \\
\hline & & & OR & LCI & UCI & $P$ value & $\begin{array}{l}\text { Trend } \\
\mathbf{P} \text { value }\end{array}$ & AIC \\
\hline \multicolumn{9}{|c|}{ Frailty definition: Fried's phenotype } \\
\hline \multirow[t]{4}{*}{ Accumulation model } & 0 & 940 & Ref & & & & $<0.001$ & 1192.5 \\
\hline & 1 & 211 & 2.02 & 1.23 & 3.34 & 0.006 & & \\
\hline & 2 & 118 & 2.52 & 1.37 & 4.62 & 0.003 & & \\
\hline & 3 & 73 & 3.53 & 1.65 & 7.55 & 0.001 & & \\
\hline \multirow{4}{*}{$\begin{array}{l}\text { Adjusted }^{*} \\
\text { accumulation model }\end{array}$} & 0 & 940 & Ref & & & & 0.160 & 1105.3 \\
\hline & 1 & 211 & 1.44 & 0.88 & 2.33 & 0.145 & & \\
\hline & 2 & 118 & 1.60 & 0.89 & 2.86 & 0.117 & & \\
\hline & 3 & 73 & 1.83 & 0.90 & 3.72 & 0.094 & & \\
\hline \multicolumn{9}{|c|}{ Frailty definition: Rockwood's Index } \\
\hline \multirow[t]{4}{*}{ Accumulation model } & 0 & 940 & Ref & & & & $<0.001$ & 1262.1 \\
\hline & 1 & 211 & 2.34 & 1.41 & 3.86 & 0.001 & & \\
\hline & 2 & 118 & 3.06 & 1.64 & 5.71 & $<0.001$ & & \\
\hline & 3 & 73 & 2.56 & 1.22 & 5.34 & 0.013 & & \\
\hline \multirow{4}{*}{$\begin{array}{l}\text { Adjusted }^{*} \\
\text { accumulation model }\end{array}$} & 0 & 940 & Ref & & & & 0.029 & 1211.1 \\
\hline & 1 & 211 & 1.77 & 1.10 & 2.85 & 0.020 & & \\
\hline & 2 & 118 & 2.05 & 1.14 & 3.69 & 0.016 & & \\
\hline & 3 & 73 & 1.54 & 0.76 & 3.13 & 0.231 & & \\
\hline
\end{tabular}

${ }^{*}$ Adjusted for age and gender. Significant values $(p<0.05)$ shown in bold.

AIC, Akaike information criterion; LCl, lower confidence interval; MIHL, minimum income for healthy living; UCl, upper confidence interval.

\section{DISCUSSION}

The present paper's results come from secondary analysis of an appropriate subset of a large nationally representative sample of older people in England. In answer to our main research questions, we found that living below the minimum income for healthy living of people aged 65 years and older in 2002 predicted frailty 6 years later, irrespective of whether frailty was measured by Fried's phenotype criteria or Rockwood's Index score. Adjustment for age and sex substantially attenuated the observed associations, but the associations remained statistically significant. In addition, we found some evidence that the relationship is cumulative and influenced by the duration of exposure to living below $\mathrm{MIHL}_{65}$. Here the evidence is more debatable: the ORs increased linearly only for Fried's phenotype measure of frailty, but not for the Rockwood scores; and only the Rockwood scores were statistically significant after adjustment for age and gender.

In answer to our subsidiary research questions: (a) Do the two measures of frailty relate differently to $\mathrm{MIHL}_{65}$ ? The associations between MIHL $_{65}$ in 2002 and frailty in 2008 were similar for both Fried's phenotype and Rockwood's Index. Therefore, the choice between them could be a question of practicalities (cost of nurse visit required to use Fried's phenotype vs a respondent unfriendly list of up to 60 items required for Rockwood's Index); (b) Does
MIHL $_{65}$ add anything to conventional economic measures of income at older ages? There was some evidence that MIHL $_{65}$ was a better predictor of frailty than the routinely used less than $60 \%$ of median income. The main strength of MIHL $_{65}$ may be its biological plausibility; (c) Does MIHL $_{65}$ add anything to the age and gender relationships to frailty? After adjustment for age and gender, $\mathrm{MIHL}_{65}$ 's association with frailty remained statistically significant (except for the accumulated model for Fried's phenotype). This suggests an independent relationship between MIHL $_{65}$ and frailty; however, earlier exposures to MIHL before age 65 years were not explored.

The absence of an association between accumulated MIHL $_{65}$ and frailty measured by Fried's phenotype can potentially be explained by the measurement of the exposure or the outcome. Fried's phenotype and Rockwood's Index are conceptually different and operationalised using very different methods ${ }^{22}$ and we found only moderate agreement between these measures in this study. Our findings suggest that accumulated $\mathrm{MIHL}_{65}$ is more relevant to the accumulation of deficits, than to the presence of a frailty phenotype. Specifically, our measurement of accumulated $\mathrm{MIHL}_{65}$ may be related to the accumulation of additional deficits sufficient to be classified as frail on Rockwood's Index, but not sufficient to lead to changes in phenotype criteria. Our exposure, 
accumulated $\mathrm{MIHL}_{65}$, is sensitive to changes in the circumstances of individuals and couples. For example, participants living or working circumstances may change between survey waves. These changes in circumstances will influence whether or not they meet the threshold for $\mathrm{MIHL}_{65}$, and these changes in circumstances are also known to be associated with frailty. ${ }^{23}$ Our findings may indicate that accumulated $\mathrm{MIHL}_{65}$ is sensitive to these changes in circumstances.

Accumulated MIHL is also sensitive to changes in pension levels and the cost of items required to lead a healthy life. The highest proportion of individuals living below the threshold for MIHL $_{65}$ was observed in 2002 $(18.8 \%)$. We calculated this threshold based on changes in inflation rates for each component of the $\mathrm{MIHL}_{65}$. The threshold for $\mathrm{MIHL}_{65}$ increased by only $£ 1.21$ for individuals and $£ 0.96$ for couples between 2002 and 2004 (see online supplementary file 1 ). This is due to relatively small increases in the inflation rates for the largest components of $\mathrm{MIHL}_{65}$ (food and the cost of running a home) during this period. Average increases in participants income from pension credit and other sources for our participants during this period were greater than the changes in the $\mathrm{MIHL}_{65}$ threshold; therefore, the proportion of participants below the $\mathrm{MIHL}_{65}$ threshold was lower after 2002. This highlights an important difference between the rate of changes of older adults' income and changes in the levels of income required to lead a healthy life. There is a need for further research into how differences in these rates of change over longer periods of time may influence the health of older adults.

The main limitations of the study come from sample attrition, which is a problem for all longitudinal studies, and the comparatively small size of the subset appropriate to our research questions. A further limitation is the presence of missing data on exposure and outcome variables. We have reported levels of missing data and a non-response analysis in online supplementary file 5 . There are small differences in the proportions of men and women, and prevalence of frailty between the ELSA core dataset and the subset used in our analyses. The smaller proportion of adults aged over 75 years in our subsample is likely to be an indicator of attrition due to mortality. Although these levels of attrition are common in cohort studies, ${ }^{25}$ we cannot rule out the risk of bias due to attrition and missing data. The ELSA dataset has been shown to be broadly nationally representative, ${ }^{16}$ and therefore findings may be generalisable to other older adults within the UK. However, our findings in this initial study are relevant to levels of income and costs of healthy living within a specific period of time in the UK. Further research is needed to understand whether the association between MIHL and frailty is generalisable to other cohorts, including those outside the UK, at other time periods and for other age groups.

The main strengths of the present study are the archived dataset's strength in biology and economics, which made possible the present paper's secondary analyses, and our use of Morris' concept and operationalisation of a minimum income for healthy living of those aged 65 years and older. Our results add to the literature on socioeconomic status and healthy ageing. ${ }^{62627}$ These findings should be considered in the context of what is known about health outcomes for socially vulnerable adults who have become frail. Gu and colleagues ${ }^{28}$ suggest that frail older adults with higher socioeconomic status are better equipped to deal with consequences of frailty; therefore, being less likely to require formal or informal care. For example, compared with frail adults with low socioeconomic status, those with higher socioeconomic status are likely to have: better access to health information and resources; more advanced coping strategies; better living conditions and an enhanced ability to adopt and maintain healthy lifestyle habits. This adds further urgency to the need to reduce income inequality to prevent frailty and to support frail older adults to maintain a better quality of life.

The hypothesis that $\mathrm{MIHL}_{65}$ may enhance frail and non-frail older adults' ability to adopt and maintain a healthy lifestyle is an important consideration for further research. We did not consider lifestyle as a confounder in our analyses because lifestyle is likely to be on the causal pathway between MIHL $_{65}$ and frailty and therefore should not be considered as a confounder. ${ }^{29}$ Future studies may investigate the hypothesis that lifestyle and expenditure on lifestyle mediate the relationship between $\mathrm{MIHL}_{65}$ and frailty. ELSA does not include sufficient information on lifestyle expenditure to test this hypothesis.

Our analyses report the association between MIHL $_{65}(2002-2006)$ and prevalent frailty in 2008. The unavailability of nurse visit data to measure frailty at wave 1 in 2002 meant we were unable to exclude frail participants at wave 1. For this reason, we cannot rule out reverse causality. However, the income of our participants, especially those below the $\mathrm{MIHL}_{65}$ threshold, will be made up entirely or almost entirely of pension income. It is therefore unlikely that frailty would influence whether or not an individual or couple's income meets or exceeds the threshold for MIHL $_{65}$.

The relationship between income and frailty should be viewed in the context of wider social vulnerability. Studies by Manrique-Espinoza et $a l^{30}$ and Lang et $a l^{11}$ provide evidence to suggest that the impact on frailty of income inequality may be exacerbated by inequalities in residential socioeconomic status. Lang et $\mathrm{l}^{11}$ found that the most socially vulnerable older adults live in the most economically deprived neighbourhoods. The authors reported that an individual's place of residence is associated with frailty independently of individual income. This suggests that policy interventions to reduce frailty through reduced income inequality should consider inequalities at both the individual level and neighbourhood level.

The findings of our study have an important policy implication for the prevention and care of frailty. Namely that informal and formal carers should check, wherever it is appropriate, that older people are in receipt of the 
Pension Credit Guarantee. Carers may also use their democratic influence to increase the Pension Credit Guarantee to at least the level of $\mathrm{MIHL}_{65}$.

Acknowledgements We acknowledge with gratitude the study participants of the English Longitudinal Study of Ageing (ELSA); and those who initiated and currently lead the study including James Banks, Richard Blundell, Roger Jowell, Michael Marmot, James Nazroo and Richard Suzman; as well as Jerry Morris whose ideas inspired the present work. The data were made available through the UK Data Archive. ELSA was developed by a team of researchers based at the NatCen Social Research, University College London and the Institute for Fiscal Studies. The data were collected by NatCen Social Research. The funding is provided by the National Institute of Aging in the USA, and a consortium of UK government departments co-ordinated by the Office for National Statistics. The developers and funders of ELSA and the Archive do not bear any responsibility for the analyses or interpretations presented here. We would also like to thank the reviewers for their helpful comments on the manuscript.

Contributors DB conceived the original idea for the study and drafted the initial manuscript. PNW conducted the data analysis, contributed to the design of the study and drafted sections of the final manuscript. GN contributed to the design of the study, the data analysis and drafting of the final manuscript. All authors read and approved the final manuscript.

Funding The authors have not declared a specific grant for this research from any funding agency in the public, commercial or not-for-profit sectors.

Competing interests None declared.

Patient consent for publication Not required.

Ethics approval This study was approved by National Research and Ethics Committee. Consent to participate in the study was provided by all participants.

Provenance and peer review Not commissioned; externally peer reviewed.

Data sharing statement The data sets analysed during the current study are available in the UK data service repository, https://discover.ukdataservice.ac.uk/ catalogue/?sn=5050.

Open access This is an open access article distributed in accordance with the Creative Commons Attribution Non Commercial (CC BY-NC 4.0) license, which permits others to distribute, remix, adapt, build upon this work non-commercially, and license their derivative works on different terms, provided the original work is properly cited, appropriate credit is given, any changes made indicated, and the use is non-commercial. See: http://creativecommons.org/licenses/by-nc/4.0/.

\section{REFERENCES}

1. Xue $Q L$. The frailty syndrome: definition and natural history. Clin Geriatr Med 2011;27:1-15.

2. Fried LP, Tangen CM, Walston J, et al. Frailty in older adults: evidence for a phenotype. J Gerontol A Biol Sci Med Sci 2001;56:M146-57.

3. Dent E, Chapman I, Howell S, et al. Frailty and functional decline indices predict poor outcomes in hospitalised older people. Age Ageing 2014;43:477-84.

4. Rechel B, Grundy E, Robine JM, et al. Ageing in the European Union. Lancet 2013;381:1312-22.

5. Guzman-Castillo M, Ahmadi-Abhari S, Bandosz P, et al. Forecasted trends in disability and life expectancy in England and Wales up to 2025: a modelling study. Lancet Public Health 2017;2:e307-e313.

6. Hoogendijk EO, Heymans MW, Deeg DJH, et al. Socioeconomic Inequalities in Frailty among Older Adults: Results from a 10-Year Longitudinal Study in the Netherlands. Gerontology 2018;64:157-64.
7. Hoogendijk EO, van Hout HP, Heymans MW, et al. Explaining the association between educational level and frailty in older adults: results from a 13-year longitudinal study in the Netherlands. Ann Epidemiol 2014;24:538-44.

8. Gardiner PA, Mishra GD, Dobson AJ. The effect of socioeconomic status across adulthood on trajectories of frailty in older women. $J$ Am Med Dir Assoc 2016;17-372.e1-3.

9. Szanton SL, Seplaki CL, Thorpe RJ, et al. Socioeconomic status is associated with frailty: the Women's Health and Aging Studies. J Epidemiol Community Health 2010;64:63-7.

10. Brunner EJ, Shipley MJ, Ahmadi-Abhari S, et al. Midlife contributors to socioeconomic differences in frailty during later life: a prospective cohort study. Lancet Public Health 2018;3:e313-e322.

11. Lang IA, Hubbard RE, Andrew MK, et al. Neighborhood deprivation, individual socioeconomic status, and frailty in older adults. J Am Geriatr Soc 2009;57:1776-80.

12. Morris JN, Deeming C. Minimum Incomes for Healthy Living (MIHL): next thrust in UK social policy?. Policy \& Politics 2004;32:441-54.

13. Morris JN, Wilkinson P, Dangour AD, et al. Defining a minimum income for healthy living (MIHL): older age, England. Int J Epidemiol 2007;36:1300-7.

14. Morris JN, Donkin AJ, Wonderling D, et al. A minimum income for healthy living. J Epidemiol Community Health 2000;54:885-9.

15. Rockwood K, Mitnitski A. Frailty in relation to the accumulation of deficits. J Gerontol A Biol Sci Med Sci 2007;62:722-7.

16. Marmot M, Oldfield Z, Clemens S, et al. English Longitudinal Study of Ageing: Waves 0-6, 1998-2013 [data collection]: UK Data Service. SN: 5050, 2015.

17. Hubbard RE, Lang IA, Llewellyn DJ, et al. Frailty, body mass index, and abdominal obesity in older people. J Gerontol A Biol Sci Med Sci 2010;65:377-81.

18. Gale CR, Cooper C, Sayer AA. Prevalence of frailty and disability: Findings from the english longitudinal study of ageing. Age Ageing 2015;44:162-5.

19. Ding YY. Developing physical frailty specifications for investigation of frailty pathways in older people. Age 2016;38:1-12.

20. Marshall A, Nazroo J, Tampubolon G, et al. Cohort differences in the levels and trajectories of frailty among older people in England. $J$ Epidemiol Community Health 2015;69:316-21.

21. Searle SD, Mitnitski A, Gahbauer EA, et al. A standard procedure for creating a frailty index. BMC Geriatr 2008;8:24.

22. Cesari M, Gambassi G, van Kan GA, et al. The frailty phenotype and the frailty index: different instruments for different purposes. Age Ageing 2014;43:10-12.

23. Chamberlain AM, St Sauver JL, Jacobson DJ, et al. Social and behavioural factors associated with frailty trajectories in a population-based cohort of older adults. BMJ Open 2016;6:e011410.

24. lavicoli I, Leso V, Cesari M. The contribution of occupational factors on frailty. Arch Gerontol Geriatr 2018;75:51-8.

25. Gustavson K, von Soest T, Karevold E, et al. Attrition and generalizability in longitudinal studies: findings from a 15-year population-based study and a Monte Carlo simulation study. BMC Public Health 2012;12:918.

26. Cooper R. Socioeconomic adversity-an important barrier to healthy aging. BMJ 2018;360:k1288.

27. Stringhini S, Carmeli C, Jokela M, et al. Socioeconomic status, non-communicable disease risk factors, and walking speed in older adults: multi-cohort population based study. BMJ 2018;360:k1046.

28. Gu D, Yang F, Sautter J. Socioeconomic status as a moderator between frailty and mortality at old ages. BMC Geriatr 2016;16:17-19.

29. van Stralen KJ, Dekker FW, Zoccali C, et al. Confounding. Nephron Clin Pract 2010;116:c143-c147.

30. Manrique-Espinoza B, Salinas-Rodríguez A, Salgado de Snyder N, et al. Frailty and Social Vulnerability in Mexican Deprived and Rural Settings. J Aging Health 2016;28:740-52. 